\title{
Isotopic Mixing in Carbon Monoxide Catalyzed by Zinc Oxide
}

\author{
G. Carnisio, ${ }^{*}$ F. Garbassi, ${ }^{*}$ G. Petrini, ${ }^{* 1}$ and G. Parravano ${ }^{\dagger}, 2$ \\ * Donegani Research Institute, I-28100 Novara, Italy, and † Department of Chemical \\ Engineering, University of Michigan, Ann Arbor, Michigan 48109
}

Received October 24, 1977; revised March 6, 1978

\begin{abstract}
The rate of the isotopic mixing in $\mathrm{CO}$ has been studied at $300^{\circ} \mathrm{C}$, for $\mathrm{CO}$ partial pressures from 6 to 100 Torr and a total pressure of 250 Torr on $\mathrm{ZnO}$ catalysts. Significant deviations from a first-order rate in $p_{\mathrm{CO}}$ were found. The rate of oxygen exchange between $\mathrm{ZnO}$ and gasphase $\mathrm{CO}$ was also measured and the results were employed to calculate the fraction of surface sites active for the $\mathrm{CO}$ isotopic mixing. Values on the order of 0.001 were found. The turnover rate and surface collision efficiency varied between 0.7 and $107 \mathrm{~min}^{-1}$ and 0.13 and $2.24 \times 10^{-8}$, respectively. $\mathrm{H}_{2}$ additions to $\mathrm{CO}$ increased the rate of isotopic mixing, whereas the rate of $\mathrm{H}_{2}+\mathrm{D}_{2}$ was decreased by the presence of $\mathrm{CO}$. The $\mathrm{H}_{2}+\mathrm{D}_{2}$ rate was faster than that of isotopic mixing in $\mathrm{CO}$, but as the ratio $p_{\mathrm{H}_{2}} / p_{\mathrm{CO}}$ decreased the rates became about equal.

It is argued that on $\mathrm{ZnO}$ samples, in which the rate of $\mathrm{CO}$ isotopic mixing and the rate of $\mathrm{ZnO}-\mathrm{CO}$ oxygen exchange were influenced in a similar manner by the $\mathrm{CO}$ pressure, the isotopic mixing in $\mathrm{CO}$ took place via the $\mathrm{ZnO}$ oxygen, while oxide oxygen participation was not kinetically significant for $\mathrm{ZnO}$ samples in which the two reactions had different kinetics. The crucial factor controlling the path followed by the isotopic mixing in $\mathrm{CO}$ seems to be the surface $\mathrm{Zn} / \mathrm{O}$ ratio, since a close correlation was found between the former and the reaction kinetics of the $\mathrm{CO}$ isotopic mixing reaction. Solid-state conditions which may vary the $\mathrm{Zn} / \mathrm{O}$ surface ratio (foreign additions) are indicated. The implications of these findings to the problem of product selectivity from $\mathrm{CO}-\mathrm{H}_{2}$ mixtures reacting on metal oxide surfaces are discussed.
\end{abstract}

Product distribution in catalytically reacting mixtures of $\mathrm{CO}$ and $\mathrm{H}_{2}$ is governed by several physicochemical conditions. Among these conditions are the nature and stoichiometry of CO adsorption, the structure of the adsorbate, and the coordination between the adsorbate structure and surface sites. Information on the nature of $\mathrm{CO}$ adsorption is particularly important when considering metal oxide catalysts, the surfaces of which possess a wide range of sites for adsorption and reaction. There is already a considerable amount of information on the adsorption modes of $\mathrm{CO}$ at metal oxide surfaces. With few exceptions

1 To whom correspondence should be sent.

2 Deceased on April 1, 1978.
(1) this information was obtained from observations on static and/or dynamic adsorption effects (ir, LEED, ESCA, adsorption volumetry), without concomitant measurements on the reactivity of each adsorption mode. The correlation between adsorption and reactivity was generally suggested by observations on additional properties of the reacting system.

To clarify the relation between the nature of the adsorption and its reactivity, measurements on both properties must be carried out simultaneously, and the effect on them of various operational factors must be directly assessed. For this purpose, isotopic exchange reactions are particularly 
suitable since they provide information simultaneously on the thermodynamics and kinetics of adsorption, thus enabling one to establish a direct link between the nature of the adsorption isotherm and the reaction efficiency.

To examine the reactive adsorption of $\mathrm{CO}$ we have employed the isotopic mixing reaction,

$$
\begin{aligned}
& { }^{13} \mathrm{C}^{16} \mathrm{O}(\mathrm{g})+{ }^{12} \mathrm{C}^{18} \mathrm{O}(\mathrm{g}) \rightarrow \\
& { }^{13} \mathrm{C}^{18} \mathrm{O}(\mathrm{g})+{ }^{12} \mathrm{C}^{16} \mathrm{O}(\mathrm{g}),
\end{aligned}
$$

where $\mathrm{g}$ refers to gas phase, and observed the rate of reaction (1) as a function of the partial pressure of $\mathrm{CO}$, in the presence and absence of $\mathrm{H}_{2}$. To extend this analysis, the rate of the isotopic exchange between $\mathrm{H}_{2}$ and $\mathrm{D}_{2}$, namely,

$$
\mathrm{H}_{2}(\mathrm{~g})+\mathrm{D}_{2}(\mathrm{~g}) \rightarrow 2 \mathrm{HD}(\mathrm{g})
$$

was measured simultaneously with the exchange in reaction (1). $\mathrm{ZnO}$ was chosen as a catalytic agent for reaction (1) and (2). The choice was suggested by past studies (2), which have shown that solidstate additions to $\mathrm{ZnO}$ influence its catalytic activity for reaction (2). Thus, if $\mathrm{H}_{2}$ adsorption is kinetically significant in the $\mathrm{CO}+\mathrm{H}_{2}$ reaction, the rate of the latter should be influenced by additions to $\mathrm{ZnO}$. Furthermore, it has been reported that on $\mathrm{ZnO}$ the product distribution from $\mathrm{CO}+\mathrm{H}_{2}$ mixtures is a function of the redox level of the oxide (3); the effect has been traced to different adsorption modes of $\mathrm{CO}$ which are related to redox conditions of the $\mathrm{ZnO}$ surface. On a broader perspective, a knowledge of the adsorption characteristics of catalytically reacting $\mathrm{CO}+\mathrm{H}_{2}$ and the role of the former in the formation of hydrocarbons versus oxygenated products seems to be an essential prerequisite toward building a satisfactory model for the $\mathrm{CO}+\mathrm{H}_{2}$ synthesis reaction and for deriving predictive correlations for technological applications.
TABLE 1

Chemical Composition, BET Surface Area, and Excess Zine for ZnO Samples

\begin{tabular}{cccc}
\hline Sample & $\begin{array}{c}\text { Addition } \\
\left(\text { at } \% \times 10^{2}\right)\end{array}$ & $\begin{array}{c}\text { Surface } \\
\text { area } \\
\left(\mathrm{m}^{2} / \mathrm{g}\right)\end{array}$ & $\begin{array}{c}\text { Excess } \\
\text { zinc }^{b} \\
(\mathrm{ppm} \\
\text { by wt })\end{array}$ \\
\hline Series $\mathrm{A}$ & & & \\
$\mathrm{ZnO}+\mathrm{Ga}$ & 0.69 & 0.53 & 3.0 \\
$\mathrm{ZnO}+\mathrm{Ge}$ & 4.82 & 2.49 & 5.4 \\
$\mathrm{ZnO}+\mathrm{Li}$ & 43.4 & 0.20 & 10 \\
$\mathrm{ZnO}+\mathrm{Re}$ & 0.96 & 0.69 & 3.6 \\
$\mathrm{Series} \mathrm{B}$ & & & \\
$\mathrm{ZnO}$ & - & 1.09 & 10 \\
$\mathrm{ZnO}+\mathrm{K}{ }^{c}$ & 4.58 & 0.86 & 3.5 \\
$\mathrm{ZnO}+\mathrm{Cr}{ }^{c}$ & 11.8 & 2.05 & $-c$ \\
$\mathrm{ZnO}+\mathrm{Cu}$ & 10.5 & 2.10 & 21 \\
$\mathrm{ZnO}+\mathrm{Fc}$ & 9.98 & 1.99 & 1.2 \\
$\mathrm{ZnO}(\mathrm{Kadox})$ & - & 0.35 & - \\
\hline
\end{tabular}

${ }^{a}$ By absorption spectroscopy.

${ }^{b} \pm 0.1 \mathrm{ppm}$.

- No analysis possible due to $\mathrm{Cr}$ in sample.

\section{EXPERIMENTAL}

$\mathrm{ZnO}$ samples were prepared in two batches. In one batch, $\mathrm{ZnO}$ (Merck, ACS reagent) was slurried with the appropriate amount of a metal nitrate solution, dried, and heated at $850^{\circ} \mathrm{C}$ in air for $6 \mathrm{hr}$ (Series A). In a second batch, $\mathrm{Zn}\left(\mathrm{CO}_{3}\right)_{2}$ was precipitated from $\mathrm{Zn}\left(\mathrm{NO}_{3}\right)_{2} \cdot 6 \mathrm{H}_{2} \mathrm{O}$, (Erba, c.p.), washed, slurried with a metal nitrate solution (or $\mathrm{KOH}$ for $\mathrm{ZnO}+\mathrm{K}$ ), dried, ball milled, and heated at $800^{\circ} \mathrm{C}$ for $3 \mathrm{hr}$ in air. The ball milling and heating sequence was repeated for an additional $3 \mathrm{hr}$ (Series B). A sample of $\mathrm{ZnO}$ (Kadox, N.J. Zinc Co.) was also employed. Sample homogeneity was checked by chemical analysis on different aliquots of the same sample. Chemical composition and BET surface area of the $\mathrm{ZnO}$ preparations are reported in Table 1.

Bulk characterization of the $\mathrm{ZnO}$ samples was carricd out by $\mathrm{X}$ ray, and chemical 
analysis was used to determine the stoichiometric Zn excess (4), while surface composition was measured by Auger spectroscopy (Physical Electronics Industries) using a $3-\mathrm{keV}$ electron beam, a $50-\mathrm{A}$ current, a $3-\mathrm{V}$ modulation amplitude, and a time constant of 0.001 sec. Surface composition was calculated by means of the equation,

$$
C_{X}=\left[\left(H_{X} / f_{X}\right) /\left(\sum_{n} H_{n} / f_{n}\right)\right] \times 100
$$

where $C_{X}$ is the atom percentage of element $X(\mathrm{O}, \mathrm{Zn}) ; H_{X}$ and $f_{X}$ are the peak height and sensitivity factor for $X$. ${ }^{13} \mathrm{C}^{16} \mathrm{O}$, 90.5 at \% ${ }^{13} \mathrm{C}$ (Merck, Sharp, and Dhome), and ${ }^{12} \mathrm{C}^{18} \mathrm{O}, 99.8$ at $\%{ }^{18} \mathrm{O}$ (Gesellschaft fur Kernforschung, Karlsruhe) were diluted with high-purity $\mathrm{He}, \mathrm{H}_{2}, \mathrm{D}_{2}$, and $\mathrm{N}_{2}$ as needed. The gas mixture was used without further purification. A typical isotopic feed composition was (percentage, $\mathrm{v} / \mathrm{v}$ ) : ${ }^{12} \mathrm{C}^{16} \mathrm{O}, 4.75 ;{ }^{13} \mathrm{C}^{16} \mathrm{O}, 45.2 ;{ }^{12} \mathrm{C}^{18} \mathrm{O}, 49.95$; ${ }^{13} \mathrm{C}^{18} \mathrm{O},<0.1$. For reaction (2) the ratio $\mathrm{D}_{2} / \mathrm{H}_{2}=0.05$ was used throughout. $\mathrm{By}$ suitable additions of $\mathrm{He}$, all runs were made at a total pressure of 250 Torr. The rate of reaction (1) was followed in an all-glass system having a total volume of $300 \mathrm{~cm}^{3}$ and including the reactor, a recycle loop, and a magnetically driven pump. Gas samples were periodically withdrawn and analyzed by mass spectrometry (EAI 250B).

Generally, $0.5 \mathrm{~g}$ of catalyst ( $35-50 \mathrm{mesh})$ was diluted to $3 \mathrm{~cm}^{3}$ with $\mathrm{Al}_{2} \mathrm{O}_{3}$ (Alcoa Tab T61) and loaded into the reactor, heated in $\mathrm{O}_{2}$ (200 Torr) at $400^{\circ} \mathrm{C}$ for 10 min, and cvacuated. The pretreatment was repeated twice, followed by cooling to reaction temperature. These conditions were found by ir spectroscopy to clean effectively the adsorbed $\mathrm{ZnO}$ surface of $\mathrm{CO}$. With the enriched $\mathrm{CO}$ samples employed it was convenient to follow the course of the reaction by monitoring the ratio of mass 30 to mass 31 ; this ratio decreased from the initial value of 20 to about 1 at equilibrium, thus providing an accurate
$( \pm 1 \%)$ record of the mass ratio as a function of time. Reaction conversions of 70 to $80 \%$ were easily followed. Partial pressures of CO ranged between 6 and 100 Torr. In all $\mathrm{ZnO}$ preparations an initial period of timedependent reaction rate was observed in the case of reaction (2). The length of this period decreased with increasing number of reruns, until it disappeared altogether for a sufficiently large number of runs. The presence or the length of the initial transient period did not influence the value of the steady rate. To eliminate this effect, prior to each run $\mathrm{ZnO}$ samples were treated at $400^{\circ} \mathrm{C}$, evacuated $\left(<10^{-3}\right.$ Torr) for $2 \mathrm{hr}$, and cooled to $300^{\circ} \mathrm{C}$; 300 Torr of $\mathrm{H}_{2}$ was admitted and then evacuated $\left(<10^{-3}\right.$ Torr $)$, and the reaction mixture was introduced. No reaction on the $\mathrm{Al}_{2} \mathrm{O}_{3}$ diluent or reactor walls was detected at $300^{\circ} \mathrm{C}$. At this temperature the reaction rate was found to be independent of the speed of the recycle pump when operated between 9 and 90 liters $/ \mathrm{hr}$, with the latter rate being employed for all runs. The reaction rate was not influenced by the sequence with which the partial pressure of $\mathrm{CO}$ was varied. No formation of $\mathrm{CO}_{2}$ or other products (alcohols) was detected in either the presence or absence of $\mathrm{H}_{2}$. A few measurements on $\mathrm{CO}$ adsorption were carried out in a conventional volumetric apparatus employing a capacitance pressure gauge. Gas samples were analyzed at the end of the adsorption runs and no $\mathrm{CO}_{2}$ was detected.

An estimate of the error in the kinetic parameters gave $\pm 30 \%$ for $k^{\circ}$ and approximately $\pm 15 \%$ for $m, n$, and $z$. These estimates were confirmed experimentally.

\section{RESULTS}

\section{Characterization of $\mathrm{ZnO}$ Samples}

For all samples investigated X-ray diffraction showed the presence of one phase only and no appreciable deviation from the literature value of the unit cell param- 
eter of $\mathrm{ZnO}(3.249 \AA)$. The results of the excess $\mathrm{Zn}$ analysis are reported in Table 1 . The effect of $\mathrm{Li}$ in increasing the excess $\mathrm{Zn}$ concentration is well known, whereas that of $\mathrm{Cu}$ may be rationalized assuming that $\mathrm{Cu}$ was dissolved in $\mathrm{ZnO}$ as $\mathrm{Cu}_{2} \mathrm{O}$. Surface analysis by Auger spectroscopy is reported in Table 2.

The data in Table 2 reveal two significant effects. Surface concentration of the additions was about two orders of magnitude larger than bulk concentration (Table 1), and the $\mathrm{Zn} / \mathrm{O}$ ratio ranged from 1.11 to 1.39 for Series A samples and from 2.22 to 2.44 for Series B samples, whereas a value of 0.84 was found for $\mathrm{ZnO}$ Kadox. The reported high values for the $\mathrm{Zn} / \mathrm{O}$ ratio falling in two distinct ranges for the two series of samples indicate that the effect of the addition on the surface stoichiometry was secondary to that of the preparative conditions. ZnO Kadox, which is obtained by direct oxidation of $\mathrm{Zn}$ metal, had probably been subjected to higher temperatures than those experienced by Series $A$ and $B$ samples. This is reflected in a $\mathrm{Zn} / \mathrm{O}$ ratio closer to the correct bulk stoichiometry. In the calculation of the $\mathrm{Zn} / \mathrm{O}$ ratios reported in Table 2 an Auger sensitivity factor for $\mathrm{Zn}$ of 0.435 (referred to a sensitivity factor of 1 for oxygen) was employed, instead of the more common value of 0.350 . The value of 0.435 was obtained by means of measurements on the $(11 \overline{2} 0)$ face of single-crystal $\mathrm{ZnO}$, the $\mathrm{Zn} / \mathrm{O}$ ratio of which is 1 . Consequently, the $\mathrm{Zn} / \mathrm{O}$ values reported in Table 2 represent a lower limit for the Zn content. The high $\mathrm{Zn}$ content at the surface is unexpected since it cannot be the result of electron beam damage. In fact no change in the $\mathrm{Zn} / \mathrm{O}$ ratio with time was noticed and the majority of past studies confirm the stability of $\mathrm{ZnO}$ surfaces under Auger conditions (5). Indeed, the large difference in the $\mathrm{Zn} / \mathrm{O}$ ratio among the samples is not consistent with an unstable $\mathrm{ZnO}$ surface; specifically, $\mathrm{ZnO}$ Kadox should not
TABLE 2

Surface Composition of $\mathrm{ZnO}$ Samples

\begin{tabular}{ccc}
\hline Sample & $\begin{array}{c}\text { Addition } \\
\text { (at\%) }\end{array}$ & $\mathrm{Zn} / \mathrm{O}$ \\
\hline Series A & & \\
$\mathrm{ZnO}+\mathrm{Ga}$ & $-^{a}$ & 1.28 \\
$\mathrm{ZnO}+\mathrm{Ge}$ & 2.9 & 1.35 \\
$\mathrm{ZnO}+\mathrm{Li}$ & $-{ }^{\circ}$ & 1.11 \\
$\mathrm{ZnO}+\mathrm{Re}$ & 4.0 & 1.39 \\
Series B & & \\
$\mathrm{ZnO}$ & & 2.38 \\
$\mathrm{ZnO}+\mathrm{K}$ & 1.3 & 2.38 \\
$\mathrm{ZnO}+\mathrm{Cr}$ & 3.9 & 2.22 \\
$\mathrm{ZnO}+\mathrm{Cu}$ & $\ldots-c$ & 2.27 \\
$\mathrm{ZnO}+\mathrm{Fe}$ & 3.1 & 2.44 \\
$\mathrm{ZnO}$ (Kadox) & $\ldots$ & 0.84 \\
\hline
\end{tabular}

a Concentration too low for detection.

${ }^{b}$ No reference spectra available.

${ }^{c}$ A $920-\mathrm{eV}$ peak overlaps with $\mathrm{Zn}$ peak.

have shown an oxidized surface. One sample from Series A and one sample from Series B were submitted to Auger surface analysis after their use as catalysts for reaction (1). No substantial difference in the $\mathrm{Zn} / \mathrm{O}$ ratio, as recorded prior to reaction, was discovered. Auger analysis also indicated the presence of $\mathrm{C}$ and $\mathrm{S}$, the concentration $(\approx 5$ atom $\%$ ) of which was nearly constant for all the $\mathrm{ZnO}$ preparations.

\section{Isotopic Mixing in Carbon Monoxide}

The derivation of the rate equation for reaction (1) was carried out assuming a sequence of two adsorption-desorption reaction steps, namely,

$$
\begin{gathered}
{ }^{13} \mathrm{C}^{16} \mathrm{O}(\mathrm{g})+{ }^{18} \mathrm{O}(\mathrm{s}) \rightarrow \\
{ }^{13} \mathrm{C}^{18} \mathrm{O}(\mathrm{g})+{ }^{16} \mathrm{O}(\mathrm{s}) \\
{ }^{12} \mathrm{C}^{18} \mathrm{O}(\mathrm{g})+{ }^{16} \mathrm{O}(\mathrm{s}) \rightarrow \\
{ }^{12} \mathrm{C}^{16} \mathrm{O}(\mathrm{g})+{ }^{18} \mathrm{O}(\mathrm{s}) \\
{ }^{13} \mathrm{C}^{16} \mathrm{O}(\mathrm{g})+{ }^{12} \mathrm{C}^{18} \mathrm{O}(\mathrm{g}) \rightarrow \\
{ }^{13} \mathrm{C}^{18} \mathrm{O}(\mathrm{g})+{ }^{12} \mathrm{C}^{16} \mathrm{O}(\mathrm{g})
\end{gathered}
$$

where s refers to the adsorbed phase. Since 


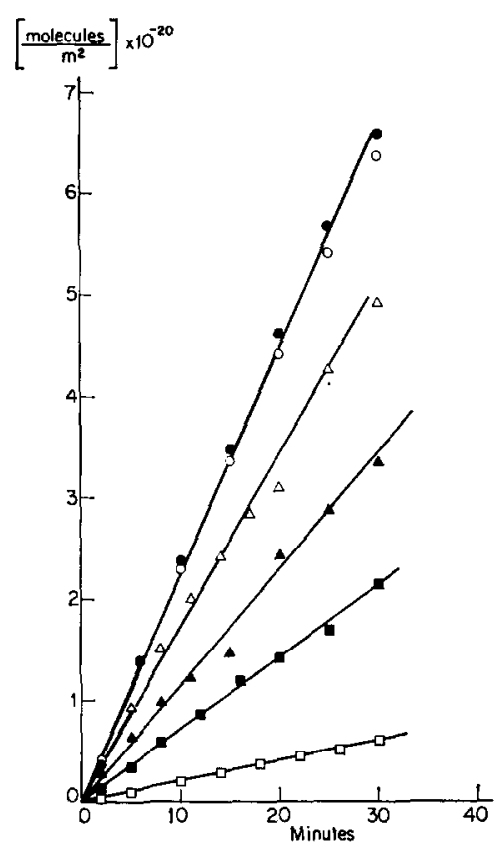

FIa. 1. Conversion versus time for reaction (1) on $\mathrm{ZnO}+\mathrm{K}$ at $300^{\circ} \mathrm{C}$. $p_{\text {Co }}$ (Torr): $(\bullet, 0) 81.0$,

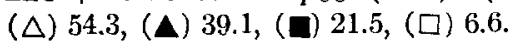

the reacting system is at equilibrium, the rates of reaction steps (1a) and (1b) are similar to the rate of the overall equilibration reaction (1). Neglecting kinetic isotope effects and gas-solid oxygen exchange and considering reaction step (1a), the rate is

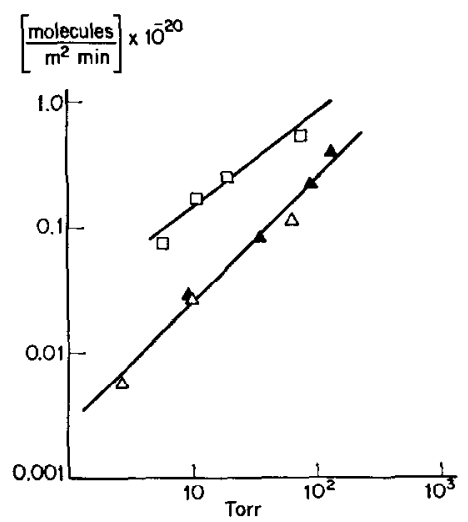

FIg. 2. Rate $v_{\mathrm{e}}$ for reaction (1) versus $p_{\text {Co }}$ on $\mathrm{ZnO}$ Kadox (A), $\mathrm{ZnO}+\mathrm{Ga}(\triangle)$, and $\mathrm{ZnO}+\mathrm{Ge}$ (口) at $300^{\circ} \mathrm{C}$. given by the expression,

$$
-\frac{1}{w} \frac{V}{R T} \frac{d p_{29}}{d t}=k_{\mathrm{c}}^{\prime} p_{29}-k_{\mathrm{c}}^{\mathrm{b}} p_{31},
$$

where $w, V, R, T, p_{29}, k_{\mathrm{e}}^{\prime}$, and $k_{\mathrm{c}}{ }^{\mathrm{b}}$ are the catalyst weight, volume of the catalyst bed, gas constant, reactor temperature, partial pressure of ${ }^{13} \mathrm{C}^{16} \mathrm{O}$, and rate coefficients, respectively, of forward and reverse reaction step (1a). The rate coefficients, $k_{\mathrm{e}}^{\prime}$ and $k_{\mathrm{c}}{ }^{\mathrm{b}}$ are dependent upon temperature and $p_{29}$. After introducing the molar fraction of ${ }^{13} \mathrm{C}^{16} \mathrm{O}, \quad x_{29}=\left(p_{13 \mathrm{C} 16 \mathrm{O}}\right) /\left(p_{\mathrm{CO}}\right)_{\text {total }}$, eliminating $k_{\mathrm{e}}{ }^{\mathrm{b}}$ by means of the equilibrium conditions, $k_{\mathrm{e}}^{\prime}\left(p_{29}\right)=k_{\mathrm{e}}{ }^{\mathrm{b}}\left(p_{31}\right)_{\infty}$, and integrating and solving for $k_{\mathrm{e}}^{\prime}, \mathrm{Eq}$. (3) yields

$$
k_{c}^{\prime}=\frac{2.3 V}{w R T t} \beta_{\infty} \log \frac{1}{1-\alpha_{c}}
$$

[expressed in moles per (grams of catalysts $\cdot$ atmospheres $\cdot$ minutes $)]$, where $\beta_{\infty}=$ $\left(p_{31} / p_{29}{ }^{\circ}\right)$ and the conversion,

$$
\begin{gathered}
\alpha_{e}=\frac{\beta-\beta_{0}}{\beta_{\infty}-\beta_{0}}=\frac{\left(x_{2 y}\right)_{o}-\left(x_{29}\right)_{t}}{\left(x_{29}\right)_{o}-\left(x_{29}\right)_{\infty}} \\
=\frac{\left(x_{31}\right)_{t}-\left(x_{31}\right)_{o}}{\left(x_{31}\right)_{\infty}-\left(x_{31}\right)_{o}} .
\end{gathered}
$$

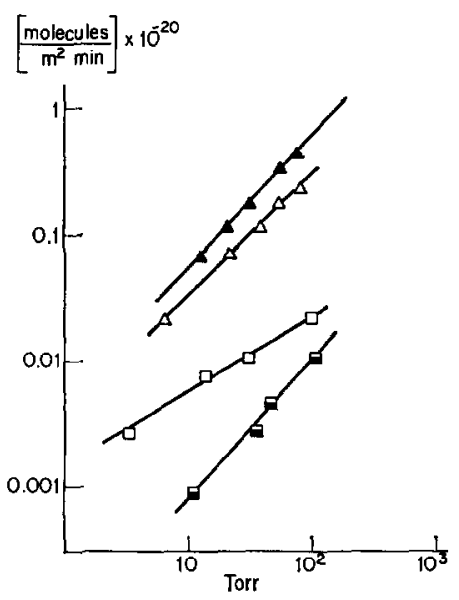

FIG. 3. Rate $v_{\mathrm{c}}$ for reaction (1) versus $p_{\mathrm{co}}$ on

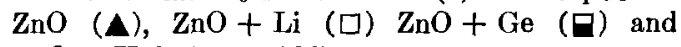
$\mathrm{ZnO}+\mathrm{K}(\triangle)$ at $300^{\circ} \mathrm{C}$. 
The subscripts $\infty, o$, and $t$ refer to values at equilibrium, at the start, and at time $t$, respectively. The experimental measurements were carried out by recording the ratio $\gamma=x_{30} / x_{31}$ as a function of time. Since

$$
\begin{aligned}
\frac{\gamma_{t}-\gamma_{\infty}}{\gamma_{t}+1}-\frac{\gamma_{0}+1}{\gamma_{0}-\gamma_{\infty}}=\frac{\left(x_{31}\right)_{\infty}-\left(x_{31}\right)_{t}}{\left(x_{31}\right)_{\infty}-\left(x_{31}\right)_{0}} \\
=1-\alpha_{\infty},
\end{aligned}
$$

from the known values of the conversion, $\alpha_{\mathrm{e}}$, could be calculated. If $A$ is the catalyst specific surface area, the reaction rate $v_{\mathrm{c}}$ is given (in molecules per square meters - minutes) by

$$
v_{\mathrm{c}}=\frac{k_{\mathrm{c}}^{\prime} N_{\mathrm{A}}}{A} p_{\mathrm{CO}}
$$

where $N_{\mathrm{A}}$ is Avogadro's number. Typical results, expressed as $\left\{(2.3 V) /(w R T)\left(\beta_{\infty}\right)\right.$ $\left.\log \left[1 /\left(1-\alpha_{c}\right)\right]\right\}$ versus time, are reported in Fig. 1.

By performing experiments at different $p_{\text {Co }}$ it was found that $v_{\mathrm{c}}$ was not always a first-order rate as expressed in Eq. (6). The experimental results on the influence of $p_{\mathrm{CO}}$ on $v_{\mathrm{e}}$ are collected in Figs. 2 and 3.

To test the effect of the presence of $\mathrm{H}_{2}$ on the rate of reaction (1) runs were performed at $300^{\circ} \mathrm{C}$ with a premixed mixture of $\mathrm{CO}$ and $\mathrm{H}_{2}+\mathrm{D}_{2}$. The results of this set of runs are reported in Figs. 4 and 5.

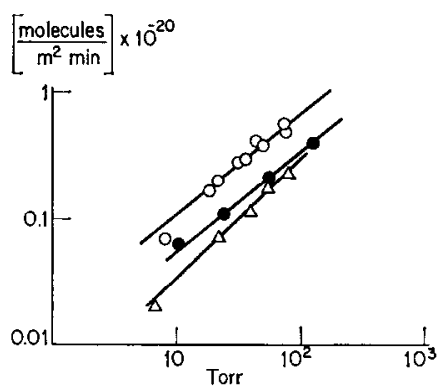

FIG. 4. Rate $v_{\mathrm{e}}$ for reaction (1) versus $p_{\mathrm{Co}}$ on $\mathrm{ZnO}+\mathrm{K}$ at $300^{\circ} \mathrm{C}$. ( $\left.\triangle\right)$ No $\mathrm{H}_{2} ;(\bullet) 50 \%(\mathrm{v} / \mathrm{v})$ $\mathrm{H}_{2} ;$ (O) $75 \%(\mathrm{v} / \mathrm{v}) \mathrm{H}_{2}$.

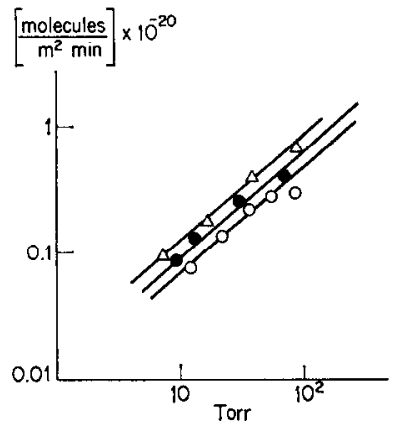

Fig. 5. Rate $v_{\mathrm{a}}$ for reaction (1) versus $p_{\mathrm{Co}}$ on $\mathrm{ZnO}+\mathrm{Cr}$ at $300^{\circ} \mathrm{C}$. (O) $\mathrm{No}_{2} ;(\bullet) 50 \%(\mathrm{v} / \mathrm{v})$ $\mathrm{H}_{2} ;(\triangle) 75 \%(\mathrm{v} / \mathrm{v}) \mathrm{H}_{2}$.

No formation of $\mathrm{H}_{2} \mathrm{O}$ was detected in these runs. At $300^{\circ} \mathrm{C}$ the presence of $\mathrm{H}_{2} \mathrm{O}$ in the reacting mixture had a strong inhibiting influence on the rate of reaction (1). After $\mathrm{H}_{2} \mathrm{O}$ inhibition, original activity could be recovered by subsequent treatment with $\mathrm{O}_{2}$ (Table 3).

Employing a commercial methanol synthesis catalyst $\left(\mathrm{ZnO}-\mathrm{Cr}_{2} \mathrm{O}_{3}\right.$, specific surface area: $76 \mathrm{~m}^{2} / \mathrm{g}$ ) under conditions of temperature and $p_{\mathrm{Co}}$ similar to those employed for the $\mathrm{ZnO}$ samples, isotopic equilibrium in reaction (1) was attained in $<2 \mathrm{~min}$.

\section{Oxygen Exchange between $\mathrm{CO}$ and $\mathrm{ZnO}$}

Early in this study it became clear that oxygen exchange between $\mathrm{CO}$ and $\mathrm{ZnO}$ took place. Although the extent of the exchange was not sufficient to produce

\section{TABLE 3}

Effect of $\mathrm{H}_{2} \mathrm{O}$ on the Rate of Reaction (1) on $\mathrm{ZnO}+\mathrm{K}$ al $300^{\circ} \mathrm{C}, p_{\mathrm{CO}}=95.5$ Torr, and Total Pressure $=250$ Torr

\begin{tabular}{cc}
$\begin{array}{c}\text { Gas-phase } \\
\text { composition }\end{array}$ & $\begin{array}{c}v_{\mathrm{c}} \\
{[\text { (molecules } /} \\
\left.\mathrm{m}^{2} \text { min }\right) \\
\left.\times 10^{-20}\right]\end{array}$ \\
\hline $\mathrm{CO}+\mathrm{He}$ & $\mathbf{0 . 5 7 5}$ \\
$\mathrm{CO}+\mathrm{He}^{2}+\mathrm{H}_{2} \mathrm{O}$ (8.5 Torr) & $\mathbf{0 . 0 0 2 2}$ \\
$\mathrm{CO}+\mathrm{He}^{a}$ & 0.75 \\
\hline
\end{tabular}

a After pretreatment, $\mathrm{O}_{2}, 400^{\circ} \mathrm{C}, 10 \mathrm{~min}$. 


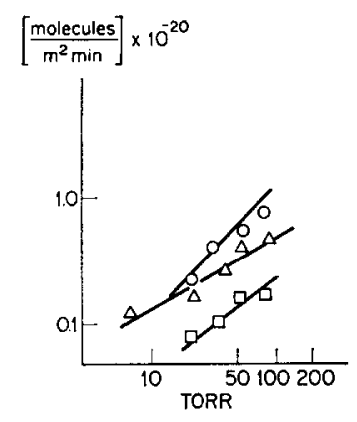

FIG. 6. Rate $v_{\mathrm{o}}$ for reaction (6) versus $p_{\mathrm{CO}}$ at $300^{\circ} \mathrm{C} . \mathrm{ZnO}(\mathrm{O}) ; \mathrm{ZnO}+\mathrm{Cr}(\square) ; \mathrm{ZnO}+\mathrm{K}(\Delta)$.

noticeable deviations from the linear conversion plots (Fig. 1), it was nevertheless deemed of interest to quantify the effect for its possible implications in the elucidation of the details of $\mathrm{CO}$ adsorption at $\mathrm{ZnO}$ surfaces. The rate of the exchange reaction, ${ }^{12} \mathrm{C}^{18} \mathrm{O}(\mathrm{g})+\mathrm{Zn}^{16} \mathrm{O} \rightarrow$

$$
{ }^{12} \mathrm{C}^{16} \mathrm{O}(\mathrm{g})+\mathrm{Zn}^{18} \mathrm{O}
$$

was expressed as the difference between the rate of disappearance of ${ }^{12} \mathrm{C}^{18} \mathrm{O}$, or

$$
d p_{30} / d t=k_{30} p_{30}-k_{28}^{\prime} p_{28}
$$

and the rate of appearance of ${ }^{13} \mathrm{C}^{18} \mathrm{O}$ [Fq. (3)]. By means of Eq. (4) and the integrated expression of Eq. (8), the forward rate coefficient of Eq. (7), $k_{0}$, is given (in moles per grams of catalyst -atmospheres $\cdot$ minutes) by

$$
\begin{array}{r}
k_{\mathrm{o}}=k_{30}-k_{31} \\
=-\frac{2.3 V}{w R T}\left[\left(x_{30}\right)_{\infty} \log \frac{1}{1-\alpha_{30}}\right. \\
\left.\quad+\left(x_{31}\right)_{\infty} \log \frac{1}{1-\alpha_{31}}\right],
\end{array}
$$

where $\alpha_{30}$ and $\alpha_{31}$ are the reaction conversions corresponding to mass 30 and 31 , respectively. Finally, the rate of reaction (7) is given (in molecules per square meters - minutes) by

$$
v_{\mathrm{o}}=\frac{k_{\mathrm{o}} N_{\mathrm{A}}}{A} p_{\mathrm{CO}} .
$$

Since multiple exchange $\left({ }^{13} \mathrm{C}^{18} \mathrm{O}-\mathrm{ZnO}\right)$ was not considered in the derivation of Eq. (9), the latter is strictly valid at $t=0$ only. However, no significant deviation from straight-line plots was observed even at moderate conversion. The experimental results of the effect of $p_{\mathrm{CO}}$ on the rate of reaction (7) are reported in Figs. 6 and 7.

\section{$\mathrm{H}_{2}-\mathrm{D}_{2}$ Equilibration}

The rate of the isotopic equilibration between $\mathrm{H}_{2}$ and $\mathrm{D}_{2}$ was derived in a manner similar to that employed for reaction (1). Assuming that only adsorption and desorption steps are kinetically significant, namcly,

$$
\begin{aligned}
\mathrm{D}_{2}(\mathrm{~g}) & \rightarrow 2 \mathrm{D}(\mathrm{s}) \\
\mathrm{H}_{2}(\mathrm{~g}) & \rightarrow 2 \mathrm{H}(\mathrm{s}) \\
2 \mathrm{D}(\mathrm{s})+2 \mathrm{H}(\mathrm{s}) & \leftrightharpoons 2 \mathrm{HD}(\mathrm{g}) \\
\mathrm{D}_{2}(\mathrm{~g})+\mathrm{H}_{2}(\mathrm{~g}) & \rightarrow 2 \mathrm{HD}(\mathrm{g})
\end{aligned}
$$

the rate of reaction (11a), which is similar to the rate of reaction (11), is given by

$$
-\frac{V}{w R T} \frac{d p_{\mathrm{D}_{2}}}{d t}=k^{\prime}{ }_{\mathrm{D}} p_{\mathrm{D}_{2}}-k_{\mathrm{D}^{\mathrm{b}}}{ }^{\mathrm{b}}
$$

where $k_{\mathrm{D}}^{\prime}$ and $k_{\mathrm{D}}{ }^{\mathrm{b}}$ are the forward and reverse rate coefficients of reaction step (11a) and $p_{\mathrm{D}_{2}}$ is the $\mathrm{D}_{2}$ partial pressure. Introducing the reaction conversion,

$$
\alpha_{\mathrm{D}}=\left[\left(x_{\mathrm{HD}}\right)_{l}-\left(x_{\mathrm{HD}}\right)_{\mathrm{o}}\right] /
$$

Fig. 7. Rate $v_{0}$ for reaction (6) versus $p_{\mathrm{CO}}$. $\mathrm{ZnO}+\mathrm{Ga}(\mathrm{O}) ; \mathrm{ZnO}+\mathrm{Re}(\square)$. 


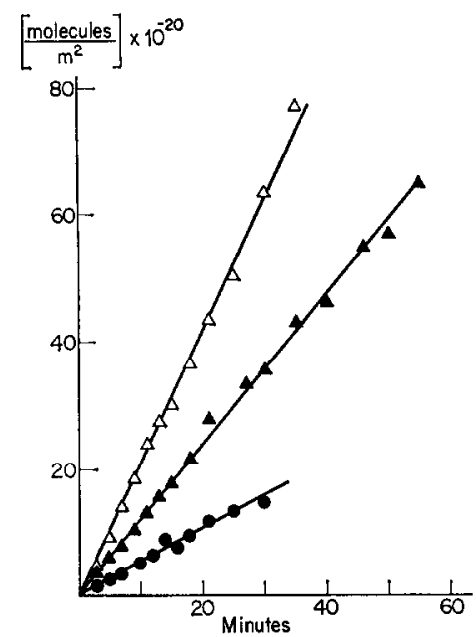

FiG. 8. Conversion versus time for reaction (11) on $\mathrm{ZnO}+\mathrm{K}$ at $300^{\circ} \mathrm{C}$. $p_{\mathrm{H}_{2}}$ (Torr): (e) 31.5 ; (A) $71.7 ;(\triangle) 196$.

where $x_{\mathrm{HD}}$ is the mole fraction of $\mathrm{HD}$; eliminating $k_{\mathrm{D}}{ }^{\mathrm{b}}$ and integrating, Fq. (12) yields

$k_{D}^{\prime}=[(2.3 V) /(w R T t)] \log \left[1 /\left(1-\alpha_{D}\right)\right]$.

The rate of reaction (11) is given (in molecules per square meters - minutes) by

$$
v_{\mathrm{D}}=\left(k_{\mathrm{D}}^{\prime} / A\right) N_{\mathrm{A}} p_{\mathrm{H}_{2}} \text {. }
$$

Linear plots of

$$
[(2.3 V) /(w R T)] \log \left[1 /\left(1-\alpha_{\mathrm{D}}\right)\right]
$$

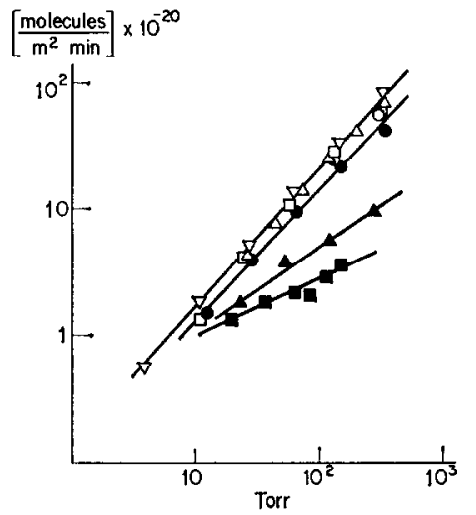

Fig. 9. Rate $v_{\mathrm{D}}$ for reaction (11) on $\mathrm{ZnO}$ versus $\left(p_{\mathrm{H}_{2}}\right)_{t}$ at $300^{\circ} \mathrm{C}$. $(O, \Delta, V)$ Different runs under similar conditions, no $\mathrm{CO}$; $(\square) 0.36 \%$ (v/v) CO; (•) $2.5 \%(\mathrm{v} / \mathrm{v}) \mathrm{CO} ;(\Delta) 24 \%(\mathrm{v} / \mathrm{v}) \mathrm{CO}$; (a) $51 \%(\mathrm{v} / \mathrm{v}) \mathrm{CO}$.

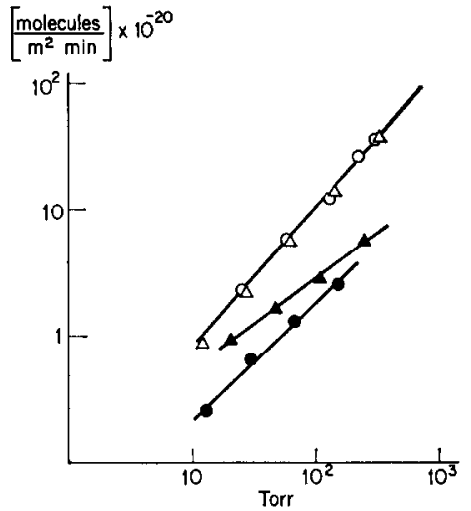

FIg. 10. Rate $v_{\mathrm{n}}$ for reaction (11) versus $\left(p_{\mathrm{H}_{2}}\right)_{t}$ on $\mathrm{ZnO}+\mathrm{Cr}_{2} \mathrm{O}_{3}$ at $300^{\circ} \mathrm{C}$. (O) No CO added; $(\triangle)$ $0.4 \%(\mathrm{v} / \mathrm{v}) \mathrm{CO} ;(\Delta) 25 \%(\mathrm{v} / \mathrm{v}) \mathrm{CO} ;(\bullet) 50 \%$ $(\mathrm{v} / \mathrm{v}) \mathrm{CO}$.

versus time were obtained in all cases (Fig. 8). On the basis of the available experimental results it was not possible to distinguish meaningfully between reaction scheme (11) and alternate adsorptiondesorption reaction sequences.

The results on $\mathrm{ZnO}, \mathrm{ZnO}+\mathrm{K}, \mathrm{ZnO}$ $+\mathrm{Cr}$, and $\mathrm{ZnO}+\mathrm{Cu}$, plotted according to Eq. (13) at different $\left(p_{\mathrm{H}_{2}}\right)_{t}$ and $300^{\circ} \mathrm{C}$, are reported in Figs. 9, 10, and 11, which include information on the effect of $\mathrm{CO}$ on the rate of reaction (11). $\mathrm{H}_{2} \mathrm{O}$ was found to have an inhibiting effect; $0.1 \% \mathrm{D}_{2}-\mathrm{H}_{2} \mathrm{O}$ exchange was also detected.

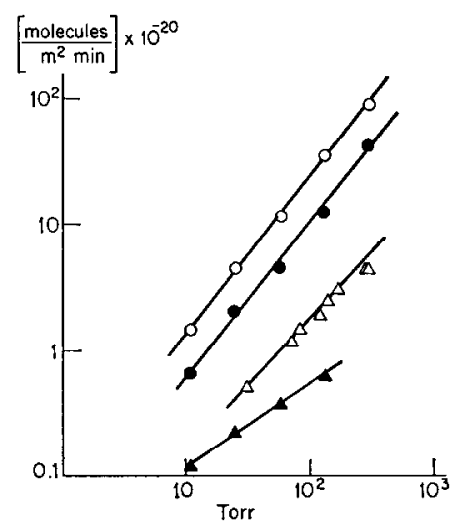

FIG. 11. Rate $v_{\mathrm{D}}$ for reaction (11) versus $\left(p_{\mathrm{H}_{2}}\right)_{t}$ on $\mathrm{ZnO}+\mathrm{K}$ at $300^{\circ} \mathrm{C}$. (O) No $\mathrm{CO}$ added; (०) $0.4 \%(\mathrm{v} / \mathrm{v}) \mathrm{CO} ;(\triangle) 25 \%(\mathrm{v} / \mathrm{v}) \mathrm{CO} ;(\boldsymbol{\Delta}) 50 \%$ (v/v) CO. 
TABLE 4

Values of the Constants $k_{0}{ }^{\circ}, k_{0}{ }^{\circ}, m_{\mathrm{c}}$, and $m_{0}$ in Eqs. (14) and (15) for Reactions (1) and (7) on $\mathrm{ZnO}$ at $300^{\circ} \mathrm{C}$

\begin{tabular}{ccccc}
\hline Sample & $k_{\mathrm{c}}{ }^{{ }_{a} a}$ & $m_{0}$ & $k_{\mathrm{o}}{ }^{{ }^{a} a}$ & $m_{\mathrm{o}}$ \\
\hline Series A & & & & \\
$\mathrm{ZnO}+\mathrm{Ga}$ & 2.1 & 0.90 & 2.0 & 0.90 \\
$\mathrm{ZnO}+\mathrm{Ge}$ & 3.3 & 0.70 & $\sim 1.0$ & 0.70 \\
$\mathrm{ZnO}+\mathrm{Li}$ & 0.2 & 0.65 & - & 0.75 \\
$\mathrm{ZnO}+\mathrm{Re}$ & 0.1 & 0.75 & 0.1 & \\
Series B & & & & 0.90 \\
$\mathrm{ZnO}$ & 2.0 & 1.0 & 0.8 & 0.58 \\
$\mathrm{ZnO}+\mathrm{K}$ & 2.1 & 1.0 & 1.50 & $\sim .61$ \\
$\mathrm{ZnO}+\mathrm{Cr}$ & 2.0 & 1.0 & 0.75 & $\sim 1.0$ \\
$\mathrm{ZnO}+\mathrm{Cu}$ & $>6$ & $\sim 1.0$ & $>6$ & 0.42 \\
$\mathrm{ZnO}+\mathrm{Fe}$ & 3.0 & 1.35 & $\sim 0.5$ & \\
$\mathrm{ZnO}$ Kadox & 1.9 & 0.90 & $\sim 1.70$ & \\
\hline
\end{tabular}

a Expressed as (molecules per square meters $\cdot$ minutes atmospheres) $\times 10^{-20}$.

\section{DISCUSSION}

\section{CO Isotopic Equilibration}

The results reported in Figs. 2 to 7 for reactions (1) and (7) may be expressed by equations of the type,

$$
v_{\mathrm{c}}=k_{\mathrm{c}}{ }^{\circ} p_{\mathrm{CO}}{ }^{m_{\mathrm{c}}}[\text { reaction (1) }]
$$

and

$$
v_{\mathrm{o}}=k_{\mathrm{o}}^{\circ} p_{\mathrm{CO}}^{m_{\mathrm{o}}}[\text { reaction (7)], }
$$

where $k_{\mathrm{c}}^{\circ}, k_{\mathrm{o}}^{\circ}, m_{\mathrm{c}}$, and $m_{\mathrm{o}}$ are constants. The calculated values of the constants are reported in Table 4. Inspection of Table 4 shows that Series A and B samples fall kinetically into two separate groups. In fact, while in samples of Series A the pressure dependence of the rates of reactions (1) and (7) was similar, this was not the case for Series B samples. Furthermore,

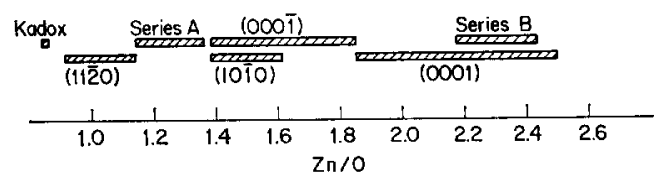

FIG. 12. Surface $\mathrm{Zn} / \mathrm{O}$ ratio for polycrystalline $\mathrm{ZnO}$ and single-crystal $\mathrm{ZnO}$ faces. the values of $k_{\mathrm{c}}^{\circ}$ and $k_{\mathrm{o}}^{\circ}$ are numerically closer for Series A than for Series B samples. Despite uncertainty in some of the numerical values the difference in kinetic behavior between the two series is striking. We suggest that this effect is an indication that, for Series A samples, the isotopic mixing reaction (1) took place through alternate oxygen exchange steps, similar to reaction (7), whereas a reaction sequence not directly involving the oxygen of $\mathrm{ZnO}$ was responsible for reaction (1) catalyzed by Series B samples. To develop this conclusion further the information in Table 2 is instructive. In fact, a consistent difference in the $\mathrm{Zn} / \mathrm{O}$ surface ratio was present in the two sets of samples. To trace the origin of this variation, AES measurements of the $\mathrm{Zn} / \mathrm{O}$ ratio were conducted on selected faces of single-crystal $\mathrm{ZnO}$ under conditions similar to those employed for powdered samples (Fig. 12). It was found that samples of Series A and Kadox had a surface $\mathrm{Zn} / \mathrm{O}$ ratio intermediate between those of the $(10 \overline{1} 0),(11 \overline{2} 0)$, and $(000 \overline{1})$ crystal faces, whereas samples of Series $B$ exhibited a value close to that of the 
$(000 \overline{1})$ crystal face. It is suggested that the $\mathrm{Zn} / \mathrm{O}$ ratio was mostly the result of the time-temperature schedule followed during sample preparation. The suggestion was tested directly by measuring the ratio on a fresh $\mathrm{ZnO}$ sample (Merck) and obtaining a value of 2.32 . Upon heating at $800^{\circ} \mathrm{C}$ the ratio decreased to 1.49 . It is also reasonable to assume that morphological conditions (i.e., different surface planes) aided in the stabilization of the varying ratios. There is, in fact, already evidence that $\mathrm{Cu}$ additions enhance the appearance of basal planes at $\mathrm{ZnO}$ surfaces (6).

Reaction steps for reaction (1) may include the dissociative adsorption of $\mathrm{CO}$ followed by recombination and desorption. Reaction (1) may also occur through the formation and decomposition of a surface adsorbate in alternate reduction and oxidation stages. For the latter reaction sequence participation of oxygen from $\mathrm{ZnO}$ is essential and, consequently, the exchange of oxygen between $\mathrm{CO}$ and $\mathrm{ZnO}$ [reaction (7)] becomes an integral part of this reaction scheme. Alternatively, $\mathrm{CO}$ may be adsorbed with the formation of associative complexes containing two or more $\mathrm{CO}$ molecules and desorbed following decomposition of the complex.

Because of the high dissociation energy of $\mathrm{CO}(255 \mathrm{kcal} / \mathrm{mole})$ dissociative chemisorption is unlikely to be a major contributing factor to reaction (1) at $300^{\circ} \mathrm{C}$.

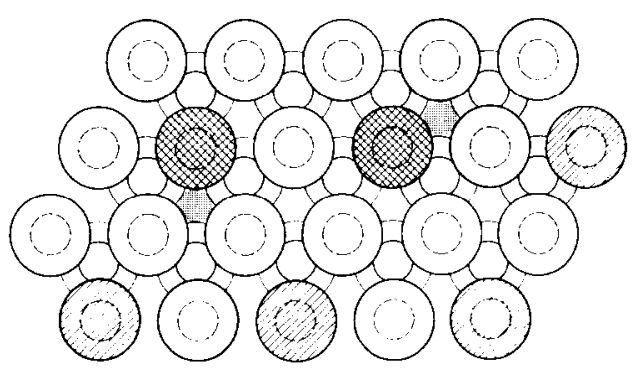

Fra. 13. Schematic view of CO chemisorption on the (000I) plane of $\mathrm{ZnO}$. (O) Topmost layer of $Z n$; $(O)$ second oxygen layer, $(\vdots)$ second $Z n$ layer;

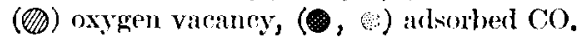

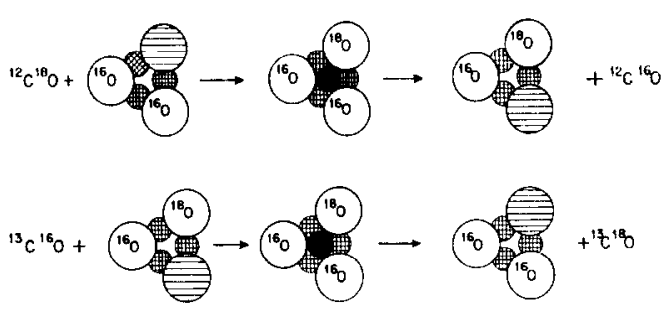

Fig: 14. Models for reactions (1) and (6) at the

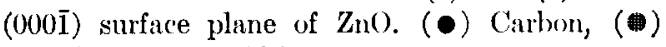
zinc, (O) oxygen, (令) oxygen vacancy.

Two-site associative adsorption seems a logical candidate and a physically plausible adsorption precursor for reactions (1) and (7). Molecular orbital considerations of the electronic configuration of the $\mathrm{CO}$ molecule do not in fact preclude the possibility of a bridged binding, or of any scheme involving both $\mathrm{C}$ and $\mathrm{O}$ bonded to the surface $(7)$.

A likely candidate for a site pair on the $(000 \overline{1})$ face for the adsorption of $\mathrm{CO}$ is the combination of the hole with threefold oxygen coordination and a neighboring oxygen vacancy (Fig. 13). The course of reaction (1) on this plane may be visualized as a sequence of adsorption and desorption steps, similar to those postulated for reaction (7) (Fig. 14). On this surface-reactive $\mathrm{CO}$, adsorption takes place on a surface essentially uncovered by $\mathrm{CO}$; assuming, then, a Langmuir formulation for $\mathrm{CO}$ adsorption the values of $m_{\mathrm{c}}$ and $m_{\mathrm{o}}$ should be in the range $0<m<1$. This is consistent with the values found experimentally (Table 5). On the other hand, it is suggested that $\mathrm{CO}$ adsorption on the more reduced surfaces of Series B samples takes place on a surface largely covered by $\mathrm{CO}$; the isotopic mixing reaction (1) thus follows a path which includes the formation and decomposition of surface CO complexes, kinetically distinct from the path leading to reaction (7). Furthermore, it may be argued that, again following a Langmuir formalism for the associative $\mathrm{CO}$ adsorption, the values of $m$ should be in the range $1<m<2$. This is 
TABLE 5

Effect of $\mathrm{H}_{2}$ on the Rate Constant, $k_{c}{ }^{\circ}$, and Exponent $m_{\mathfrak{e}}$, from Eq. (14) for Reaction (1) Catalyzed by $\mathrm{ZnO}$, Series $\mathrm{B}$, at $300^{\circ} \mathrm{C}$

\begin{tabular}{|c|c|c|c|}
\hline Sample & $p_{\mathrm{H}_{2}} / p_{\mathrm{CO}}$ & $\begin{array}{c}k_{\mathrm{c}}^{\circ} \\
{[(\text { molecules } /} \\
\left.\left.\mathrm{m}^{2} \min \text { a.tm }{ }^{m c}\right) \times 10^{-20}\right]\end{array}$ & $m_{\mathbf{o}}$ \\
\hline \multirow[t]{3}{*}{$\mathrm{ZnO}$} & $\sim^{a}$ & 2.0 & 1.00 \\
\hline & 0.96 & 0.33 & 0.31 \\
\hline & 2.94 & 1.43 & 0.66 \\
\hline \multirow[t]{3}{*}{$\mathrm{ZnO}+\mathrm{K}$} & $-^{a}$ & 2.1 & 1.00 \\
\hline & 1 & 1.65 & 0.80 \\
\hline & 3.03 & 3.25 & 0.80 \\
\hline \multirow[t]{3}{*}{$\mathrm{ZnO}+\mathrm{Cr}$} & - $^{a}$ & 2.0 & 1.00 \\
\hline & 1 & 3.6 & 0.84 \\
\hline & 3.03 & 4.7 & 0.85 \\
\hline \multirow[t]{3}{*}{$\mathrm{ZnO}+\mathrm{Cu}$} & 一 $^{a}$ & $>6.0$ & - \\
\hline & 0.5 & 0.128 & 0.32 \\
\hline & 1 & 0.095 & 0.15 \\
\hline
\end{tabular}

${ }^{a} \mathrm{CO}$ only.

consistent with the experimental values reported in Table 4 . It is worth noting that from studies on reaction (1) catalyzed by metallic surfaces, it was concluded that associative $\mathrm{CO}$ adsorption played the major role $(8)$. In this instance the adsorption intermediate may be looked upon as a headto-tail square complex with the participation of two electrons per complex derived from and shared with the surface pair site. $\pi$ bonding with the surface sites would be involved, and electrons from the metal would enter the $2 p_{z} \mathrm{CO}$ orbitals, resulting in a weakened $\mathrm{C}-\mathrm{O}$ bond.

No clear pattern emerged on the role of solid additions to $\mathrm{ZnO}$ on the rate of reaction (1) (Table 4). The surface $\mathrm{Zn} / \mathrm{O}$ ratio seemed to be the crucial factor. If the redox conditions of the $\mathrm{ZnO}$ surface played a central role, it was reasoned that variations in the nature of the controlling adsorption isotherm should also be observed whenever surface redox level was modified by the presence of gas-phase species, which would interact with the surface oxygen. $\mathrm{H}_{2}$ is an obvious candidate for this test, since it is known that the reduction rate of powdered and single-crystal $\mathrm{ZnO}$ is faster in $\mathrm{H}_{2}$ than in $\mathrm{CO}(9)$. The results of the effect of $\mathrm{H}_{2}$ are collected in Table 5 .

Inspection of Table 5 shows that the adsorption of $\mathrm{CO}$ was indeed modified by the presence of $\mathrm{H}_{2}$, as indicated by a gradual decrease of $m_{\mathrm{s}}$ as $p_{\mathrm{H}_{2}}$ increased. If two-site $\mathrm{CO}$ adsorption becomes preponderant as a result of increased oxygen vacancies at the surface, the introduction of the Langmuir factor $(1-\theta)$ (2) in the rate expression has the result of lowering the value of $m$. The presence of $\mathrm{H}_{2}$ did not have a drastic influence on $k_{\mathrm{c}}^{\circ}$; there was some evidence, though, for a higher rate of reaction (1) on $\mathrm{ZnO}+\mathrm{Cr}$ and $\mathrm{ZnO}+\mathrm{K}$ (Figs. 4 and 5), an effect of $\mathrm{H}_{2}$ on the strength of the $\mathrm{C}-\mathrm{O}$ bond in adsorbed $\mathrm{CO}$. This is known to occur on several transition metal catalysts (10). 'The strong inhibition of $\mathrm{H}_{2} \mathrm{O}$ in reaction (1) may be related to the formation of surface groups,<smiles>[14CH3]O</smiles>

the presence of which is supported by ir observations (11). 
$\mathrm{H}_{2}-\mathrm{D}_{2}$ Exchange

The rate of reaction (11) was expressed as

$$
v_{\mathrm{C}}=k_{\mathrm{h}}{ }^{\circ} p_{\mathrm{H}_{2}}{ }^{{ }_{\mathrm{H}}},
$$

where $k_{\mathrm{h}}{ }^{\circ}$ and $m_{\mathrm{H}}$ are constants. The computed values of the constants are collected in Table 6. A number of points of interest emerge from the results of Table 6. Reaction (11) was influenced by solid-state additions to $\mathrm{ZnO}$, the activity sequence being $\mathrm{ZnO}+\mathrm{K} \approx \mathrm{ZnO}+\mathrm{Cu}>\mathrm{ZnO}>$ $\mathrm{ZnO}+\mathrm{Cr}$. This is the result expected from simple considerations of the effect of the additions on the concentration of surface defects in $\mathrm{ZnO}$. The activity results further confirm earlier studies (2) and the model for reaction (11), which include the presence of surface cations abnormally charged $\left(\mathrm{Zn}^{+}\right)$or anions foreign to the lattice $\left(\mathrm{OH}^{-}\right)$.

Values of $m_{\mathrm{H}}>1$ are an indication that the reactive $\mathrm{H}_{2}$ adsorption took place on sites covered by $\mathrm{H}_{2}$. This is consistent with the observation that the rate of reaction
(11) increased with $p_{\mathrm{H}_{2}}$ (Figs. 9-11). A further interesting point is the inhibition of reaction (11) by $\mathrm{CO}$, indicating a strong competition by $\mathrm{CO}$ surface sites for reaction (11). This is in agreement with the earlier conclusion of the absence of drastic influence of $\mathrm{H}_{2}$ on the rate of reaction (1). Furthermore, when measured in the absence of $\mathrm{H}_{2}$ the rate of reaction (1) was slower than that of reaction (11); however, due to the influence of $\mathrm{CO}$ on the $\mathrm{H}_{2}-\mathrm{D}_{2}$ equilibration, the rates of reaction (1) and (11) become comparable for $p_{\mathrm{H}_{2}} / p_{\mathrm{Co}}$ ratios $<1$. Thus in $\mathrm{CO}+\mathrm{H}_{2}$ synthesis on $\mathrm{ZnO}$ for low $p_{\mathrm{H}_{2}} / p_{\mathrm{Co}}$ ratios neither $\mathrm{CO}$ nor $\mathrm{H}_{2}$ adsorption must be the controlling step. This disagrees with earlier work indicating the adsorption of $\mathrm{H}_{2}$ as the limiting step in the synthesis of methanol from $\mathrm{CO}+\mathrm{H}_{2}$ on $\mathrm{ZnO}(12)$.

\section{Turnover Rate and Reaction Efficiency}

The number of active sites per unit surface area, $\phi$, was determined from knowl-

TABLE 6

Rate Constant, $k_{\mathrm{H}}^{\circ}$, and Exponent $m_{\mathrm{H}}$ in Eq. (16) for Reaction (11) Catalyzed by $\mathrm{ZnO}$, Series $\mathrm{B}$, at $300^{\circ} \mathrm{C}$

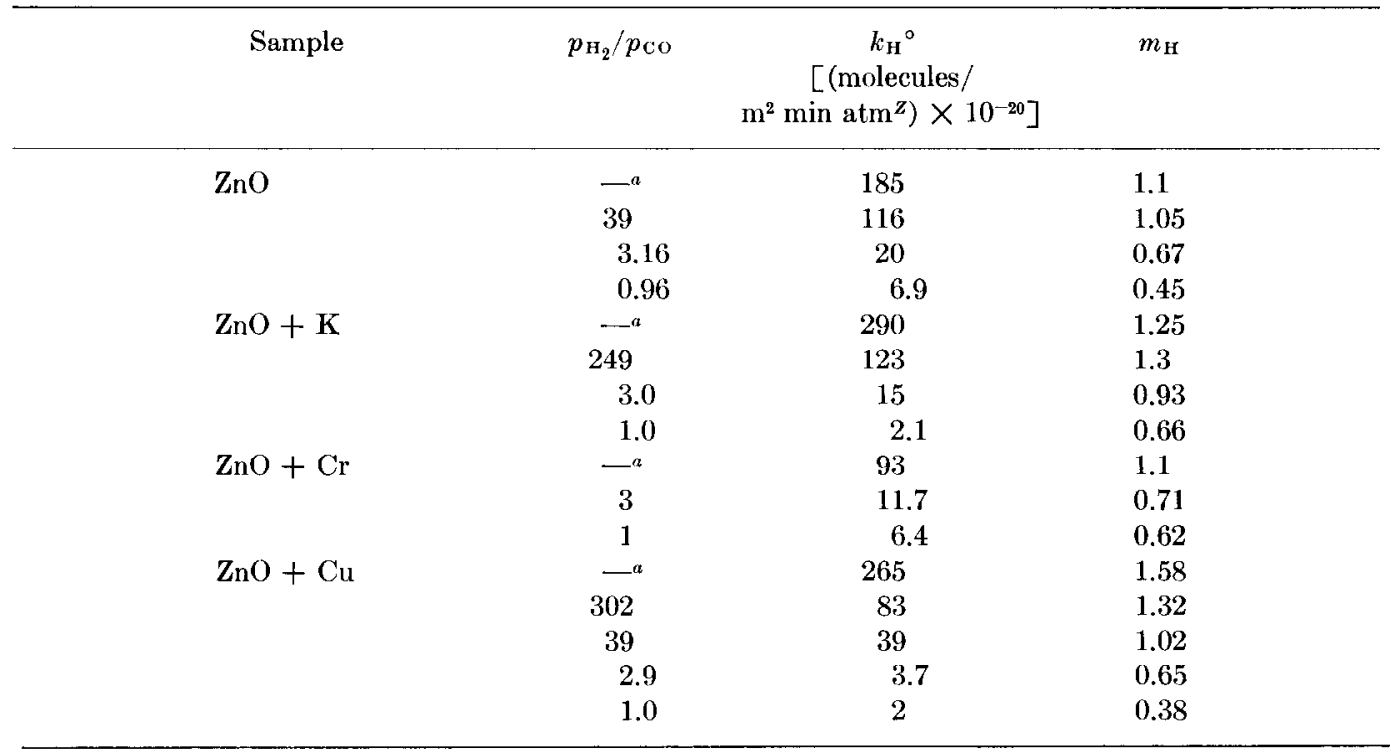

a No CO present. 
edge on the amount of solid-gas oxygen exchange (13). If $Z$ is the atom fraction of ${ }^{18} \mathrm{O}$ in the gas phase [i.e., $\left(N_{30}+N_{31}\right) / N_{\mathrm{T}}$, $N$, number of molecules] and $\left(v_{\mathrm{g}}\right)_{i}$ and $\left(v_{\mathbf{g}}\right)_{\infty}$ are the volume percentages of ${ }^{18} \mathrm{O}$ present in the gas phase initially and at a time in which the oxygen isotopic equilibrium between gas and solid is reached, respectively, a mass balance of ${ }^{18} \mathrm{O}$ between gas and adsorbed phases gives

$$
\begin{array}{r}
Z\left[\left(v_{\mathrm{g}}\right)_{i}-\left(v_{\mathrm{g}}\right)_{\infty}\right] \\
\quad=2 A \phi\left[\left(c_{\mathrm{s}}\right)_{\infty}-\left(c_{\mathrm{s}}\right)_{i}\right],
\end{array}
$$

where $A,\left(c_{\mathrm{B}}\right)_{\infty}$, and $\left(c_{\mathrm{s}}\right)_{i}$ are the surface area available, the surface concentration of ${ }^{18} \mathrm{O}$ at equilibrium, and the initial concentration, respectively. The derivation assumes that each surface site contains on the average two exchangeable oxygens and that isotopic equilibrium between gas and surface is reached by the time an analysis is made. This equilibrium condition was experimentally verified. Values of $\phi$ were calculated from Eq. (17) and used in the computation of the turnover rate

$$
\dot{N}=v_{\mathrm{c}} / \phi
$$

The values are reported in Table 7 .

The values of $\phi$ show that reactions (1) and (7) were confined to a small fraction (0.001) of the $\mathrm{ZnO}$ surface, as found previously for several oxides including $\mathrm{ZnO}$ (13). Furthermore, it is likely that, at the reaction temperature employed, oxygen interchange involved layers below the topmost. If this were the case the actual values of $\phi$ and those of the resulting surface coverage during reaction were smaller indeed. The values of $\phi$ were independent of $p_{\mathrm{CO}}$, a likely consequence of the fact that the number of active surface sites was not a fixed fraction of the total number of sites. The collision efficiency of the surface for reaction (1), $\eta$, defined by the ratio between the rate $v_{c}$, which gives the number of collisions between gaseous $\mathrm{CO}$ molecules and the $\mathrm{ZnO}$ surface leading to reaction under conditions of ad-

TABLE 7

Fraction of Active Surface, $\phi$, Turnover Rate, $\dot{N}$, and Surface Collision Efficiency, $\eta$, for Reaction (1) Catalyzed by $\mathrm{ZnO}$ at $300^{\circ} \mathrm{C}$

\begin{tabular}{lcccc}
\hline Sample & $\begin{array}{c}p_{\mathrm{CO}} \\
(\text { Torr })\end{array}$ & $\begin{array}{c}\phi \\
\left(\mathrm{m}^{-2} \times 10^{-8}\right)\end{array}$ & $\begin{array}{c}N \\
\left(\mathrm{~min}^{-1}\right)\end{array}$ & $\begin{array}{c}\eta \\
\left(\times 10^{8}\right)\end{array}$ \\
\hline $\mathrm{ZnO}$ & 20.8 & 2.7 & - & 0.35 \\
& 31.7 & 2.7 & 1.6 & 0.35 \\
& 54.7 & 2.7 & 3.1 & 0.39 \\
$\mathrm{ZnO}(\mathrm{Kadox})$ & 75.1 & 2.7 & 4.2 & 0.38 \\
$\mathrm{ZnO}+\mathrm{Cr}$ & 10.6 & 5.5 & 0.1 & - \\
& 63.0 & 5.5 & 5.0 & - \\
$\mathrm{ZnO}+\mathrm{Ge}$ & 22.0 & 2.5 & 1.2 & 0.15 \\
& 35.9 & 2.5 & 2.0 & 0.13 \\
$\mathrm{ZnO}+\mathrm{K}$ & 54.9 & 2.5 & 2.7 & - \\
& 5.9 & 2.5 & 0.7 & - \\
& 11.0 & 2.5 & 1.5 & 0.19 \\
& 20.0 & 2.5 & 2.3 & 0.21 \\
$\mathrm{ZnO}+\mathrm{Cu}$ & 6.6 & 1.4 & 0.3 & 0.18 \\
& 21.5 & 2.7 & 0.7 & 0.18 \\
& 39.1 & 2.6 & 1.1 & 2.24 \\
\hline
\end{tabular}


sorption-desorption equilibrium (exchange rate), and the total number of collisions, $\dot{n}$, is given by

$$
\begin{aligned}
& \eta=\frac{v_{\mathrm{c}}}{\dot{n}}= \frac{k_{\mathrm{c}}{ }^{\circ} p_{\mathrm{CO}}{ }^{m_{\mathrm{c}}}}{p_{\mathrm{CO}} /(2 \pi M R T)^{\frac{1}{2}}} \\
& \quad=k_{\mathrm{c}}{ }^{\circ} p_{\mathrm{CO}}{ }^{m_{\mathrm{e}}-1}(2 \pi M R T)^{\frac{1}{2}},
\end{aligned}
$$

where $M$ is the molecular weight of $\mathrm{CO}$. Values of $\eta$ are collected in the last column of Table 7. Characteristically, $\mathrm{ZnO}+\mathrm{Cu}$ preparations had surface efficiencies about one order of magnitude larger than the other samples. $\eta$ was independent of $p_{\mathrm{CO}}$, indicating that the surface steps leading to reaction (1) involved surface conditions (structural defects, redox ratios) which were not a consequence of the adsorption of $\mathrm{CO}$.

From observations on $\mathrm{CO}$ adsorption, we have calculated that $\sim 15 \times 10^{17} \mathrm{CO}$ molecules $/ \mathrm{m}^{2}$ were adsorbed at $300^{\circ} \mathrm{C}$ and 75 Torr of $\mathrm{CO}$. Dividing the number of active sites $\phi=2.7 \times 10^{8} \mathrm{~m}^{-2}$ (Table 7 ) by this number, a separate calculation of the reactive efficiency of the surface is obtained. The result is $\left(2.7 \times 10^{8}\right) /\left(15 \times 10^{17}\right)=1.9$ $\times 10^{-8}$, which is within an order of magnitude of the value $0.38 \times 10^{-8}$ calculated from the rate of reaction (1) (Table 7). Unless the accommodation coefficients were very small, adsorption of $\mathrm{CO}$ should not have been rate determining in the formation of the correct reaction complex, i.e., the bombardment rate was sufficient on all samples to account for the observed rate or reaction.

\section{CONCLUSION}

On $\mathrm{ZnO}$ surfaces the reaction of isotopic mixing in $\mathrm{CO}$ followed two distinct paths, characterized by the involvement or noninvolvement of the $\mathrm{ZnO}$ oxygen. The determining factor appeared to be the surface redox level, as obtained during the preparation of the samples. On an "oxidized" surface, oxide oxygen participation was favored. This is supportive of past ideas on the role of surface oxygen ability in the reactivity of oxide surfaces. On a "reduced" surface, $\mathrm{CO}$ complexes built by associative chemisorption provided an alternate reaction path, without the inclusion of oxide oxygen. No correlation was found between the surface $\mathrm{Zn} / \mathrm{O}$ ratio, the bulk $\mathrm{Zn}$ excess, and solid additions to $\mathrm{ZnO}$ as expected from simple controlled valency considerations.

It is tempting to relate the conclusions from the analysis of reactions (1) and (7) to the type of product distribution from reacting $\mathrm{CO}+\mathrm{H}_{2}$ mixtures. Broadly the hydrogenation of $\mathrm{CO}$ by $\mathrm{H}_{2}$ may be viewed as a two-stage reaction, the initial one consisting of the nondestructive hydrogenation of the $\mathrm{C}=\mathrm{O}$ bond leading to the formation of the $\mathrm{C}-\mathrm{OH}$ group. If the resulting $\mathrm{C}-\mathrm{O}$ bond is sufficiently stable, further hydrogenation leads to oxygenated products, whereas decreased stability could bring about the splitting of $\mathrm{II}_{2} \mathrm{O}$ and the formation of $\mathrm{CH}_{4}$. Since $\mathrm{H}_{2} \mathrm{O}$ is always found to be a reaction product, both alternatives do occur concurrently. The stability of the $\mathrm{C}-\mathrm{O}$ bond in the adsorbate should be dependent, inter alia, upon the adsorption mode of $\mathrm{CO}$ and the extent of stabilization of the bond in the presence of adsorbed hydrogen. The adsorbate complex $\mathrm{HCOH}$ has been shown to be stabilized by a formation energy of $20 \mathrm{kcal} / \mathrm{mole}$ (on $\mathrm{Fe}$ ) (14). If the electron density at the $\mathrm{C}-\mathrm{O}$ bond in the adsorbate is not high, a second hydrogenation with splitting of the $\mathrm{OH}$ group is likely to occur. This is the predominant effect at transition metal surfaces since they cannot easily bring about conditions for electron orbital hybridization in bond formation with $\mathrm{CO}$. Conversely, at metal oxide surfaces with increasing electron delocalization, $\mathrm{C}-\mathrm{O}$ bond stabilization through the participation of several oxygens in the adsorption complex is possible. This precludes the direct desorption of the complex $\mathrm{HCOH}$ with formation of formaldehyde (15); further hydrogena- 
tion brings about the formation of methanol. Thus, despite the obvious difference in the experimental conditions generally employed for methanol synthcsis from $\mathrm{CO}+\mathrm{H}_{2}$ the results discussed in the previous sections have implications for the latter reaction. Chemisorption of $\mathrm{CO}$ and $\mathrm{H}_{2}$ does not control synthesis rate. Since, at the synthesis temperature, $\mathrm{CH}_{3} \mathrm{OH}$ desorption is not likely to be kinetically significant, the slow determining step appears to be the hydrogenation of the adsorbed $\mathrm{CO}$. The presence of $\mathrm{H}_{2}$ does modify the catalytic activation of $\mathrm{CO}$. The tendency is for the hydrogen chemisorption to increase, structurally and energetically, the interaction of the adsorbed $\mathrm{CO}$ with the $\mathrm{ZnO}$ surface, a situation reminiscent of the effect of $\mathrm{H}_{2}$ on $\mathrm{N}_{2}$ chemisorption on synthetic ammonia catalysts. Despite the inability to define precisely the structural aspects of the role of $\mathrm{H}_{2}$, the present results establish the kinetic effect of $\mathrm{H}_{2}$. Selectivity to the formation of $\mathrm{CH}_{3} \mathrm{OH}$ is likely to depend upon the stalilization of a low $\mathrm{Zn} / \mathrm{O}$ ratio at the surface during the prevailing reducing conditions of the synthesis. Consequently, catalyst aging, i.e., increased production of $\mathrm{CH}_{4}$, may be related to slow surface reduction.

\section{ACKNOWLEDGMENT}

One of us (G. Parravano) acknowledges with thanks partial support of this study from the National Science Foundation through Grant No. ENG 75-14193.

\section{REFERENCES}

1. Nekipelov, V. N., and Kasatkina, L. A., Kinet. Catal. 11, 751 (1970).
2. Molinari, E., and Parravano, G., J. Amer. Chem. Soc. 75, 5233 (1953).

9. Voroshilov, I. G., Roev, L. M., Kozub, G. M., Lunev, N. K., Pavlovskii, N. A., and Rusov, M. T., Exp. Theor. Chem. 11, 256 (1975).

4. Norman, A., Analyst 89, 261 (1964).

5. Chung, M. F., and Farnsworth, H. E., Surface Sci. 22, 93 (1970); Levine, J. D., and Willis, A., Surface Sci. 29, 144 (1972); Fiermans, L., Arijs, E., Vennik, J., and Maenhout-van der Vorst, W., Surface Sci. 39, 357 (1973); Hopkins, B. J., Leysen, R., and Taylor, P. A., Surface Sci. 48, 486 (1975); Van Hove, H., and Leysen, R., Phys. Status Solidi 9, 361 (1972); Margoninski, Y., and Kirby, R. E., J. Phys. Chem. 8, 1516 (1975); Gopel, W., Ber. Bunsenges. Phys. Chem. 80, 481 (1976).

6. Klier, K., and Kobylinski, T. P., Paper No. 14.6, presented at the Fifth North American Meeting of the Catalysis Society, Pittsburgh, April 1977.

7. Coulson, C. A., "Valence," p. 222. Oxford University Press, New York, 1961.

8. Madey, T. E., Yates, J. T., Jr., and Stern, R. C., J. Chem. Phys. 42, 1372 (1975); Zhdan, P. A., Boreskov, G. K., Boronin, A. I., Egelhoff, W. E., and Vainberg, V. G., Kinet. Catal. 18, 570 (1977).

9. Grunze, M., "Struktur-und Fehlordnungs-Abhangigkeit der Reduktion von Zinkoxidoberhachen mil Kohlenmonoxid und Wasserstoff." Ph.D. Dissertation, Freien Unversitat Berlin, 1977.

10. Dalla Betta, R. A., and Shelef, M., J. Catal. 49, 383 (1977).

11. Kokes, R. J., "Catalysis" (F. Basolo and R. L. Burwell Eds.). Plenum Press, New York, 1973.

12. Leonov, V. E., Karabaev, M. M., Tsybina, E. N., and Petrishcheva, G. S., Kinet. Catal. 14, 970 (1973).

13. Winter, E. S., J. Chem. Soc, 5781, 1964.

14. Kölbel, H., Patzschke, G., and Hammer, H., Z. Phys. Chem. NF 48, 10 (1966); Blyholder, G., and Neff, L., J. Phys. Chem. 66, 1664 (1966).

15. Kölbel, H., and Tillmetz, K. D., Ber. Bunsenges. Phys. Chem. 76, 1156 (1972). 